\title{
Estrategia de PCR múltiple para la caracterización molecular simultánea de Staphylococcus aureus y enterotoxinas estafilocócicas en aislamientos de brotes de origen alimentario
}

\author{
Aníbal A. Brizzio1', Fabián A. Tedeschi², Fabián E. Zalazar² \\ 1 Servicio de Laboratorio, Agencia Santafesina de Seguridad Alimentaria (ASSAL), Santa Fe, Argentina \\ 2 Laboratorio de Práctica Profesional, Facultad de Bioquímica y Ciencias Biológicas, Universidad Nacional del \\ Litoral, Santa Fe, Argentina
}

Introducción. La intoxicación alimentaria estafilocócica es la más frecuente de las intoxicaciones alimentarias. La acción de las enterotoxinas de Staphylococcus aureus en la luz intestinal provoca una importante pérdida de agua que origina vómitos y diarrea.

Objetivo. Presentar una estrategia rápida, fiable y de bajo costo, basada en una reacción en cadena de la polimerasa $(\mathrm{PCR})$ múltiple para, simultáneamente, identificar $S$. aureus y detectar genes de las cinco enterotoxinas clásicas de S. aureus (sea, seb, sec, sed, see) en cepas de Staphylococcus spp. aisladas de alimentos.

Materiales y métodos. Se trabajó con aislamientos recuperados de 12 brotes de intoxicación alimentaria estafilocócica ocurridos en la provincia de Santa Fe, Argentina. El aislamiento y la caracterización fenotípica se llevaron a cabo mediante procedimientos estándar. La evaluación genotípica se hizo por una PCR múltiple, utilizando simultáneamente cebadores para los genes nuc, sea-see y $16 S$ rRNA.

Resultados. En las cepas analizadas se detectó $58 \%$ de portadoras de genes toxigénicos. Las toxinas sea y seb se encontraron en igual porcentaje ( $29 \%)$, mientras que las sec, sed y see se encontraron en menor e idéntica proporción (14\%). No encontramos más de un tipo diferente de enterotoxinas de $S$. aureus en los aislamientos analizados.

Conclusiones. La estrategia de PCR múltiple diseñada en este trabajo permitió identificar cepas de $S$. aureus y confirmar, al mismo tiempo, su enterotoxigenicidad. En estos momentos, nuestros esfuerzos están dirigidos a detectar los genes que codifican enterotoxinas distintas de las clásicas, a fin de conocer su incidencia en las intoxicaciones alimentarias estafilocócicas e investigar su relevancia en la salud pública de nuestro país.

Palabras clave: intoxicación alimentaria estafilocócica, Staphylococcus aureus, enterotoxinas, reacción en cadena de la polimerasa.

doi: http://dx.doi.org/10.7705/biomedica.v33i1.816

Multiplex PCR strategy for the simultaneous identification of Staphylococcus aureus and detection of staphylococcal enterotoxins in isolates from food poisoning outbreaks

Introduction: Staphylococcal food poisoning is the most frequent type of food poisoning around the world. Staphylococcus aureus enterotoxins cause significant loss of water in the intestinal lumen, followed by vomiting and diarrhea.

Objective: To report a fast, reliable and inexpensive strategy based on multiplex PCR for the simultaneous identification of $S$. aureus and detection of five classical $S$. aureus enterotoxin genes (sea, seb, sec, sed, see) in Staphylococcus spp. strains isolated from food poisoning outbreaks.

Materials and methods: We analyzed isolates from 12 food poisoning outbreaks occurred in Santa Fe province (Argentina). Isolation and phenotypic characterization were carried out by standard procedures. Genotypic analysis was performed by multiplex PCR, using primers for nuc, sea-see and $16 \mathrm{~S}$ rRNA genes simultaneously.

Results: Of all the strains tested, $58 \%$ were found to carry toxigenic genes. Sea and seb toxins were found at the same percentage (29\%) while sec, sed and see genes were found in a lower and identical proportion (14\%). We did not find more than one different type of $S$. aureus enterotoxin in the isolates analyzed.

\section{Contribución de los autores:}

Aníbal A. Brizzio: aislamiento y caracterización fenotípica de Staphylococcus aureus, análisis molecular de las cepas en estudio y escritura de manuscrito.

Fabián A. Tedeschi: análisis molecular de las cepas en estudio y escritura del manuscrito.

Fabián E. Zalazar: diseño de experiencia, discusión de resultados y escritura del manuscrito. 
Conclusions: The multiplex PCR strategy designed in this work has enabled us to identify strains of $S$. aureus and detect -at the same time- their enterotoxigenic ability. At present, our efforts are devoted to the detection of genes encoding enterotoxins other than the classical ones, in order to know their impact on staphylococcal food poisoning, as well as to investigate their relevance to our country's public health.

Key words: Staphylococcal food poisoning, Staphylococcus aureus, enteterotoxins, polymerase chain reaction.

doi: http://dx.doi.org/10.7705/biomedica.v33i1.816

Las enfermedades transmitidas por los alimentos son un problema para la salud pública a nivel mundial y son recurrentes en los países desarrollo. La más frecuente de las intoxicaciones alimentarias es la alimentaria estafilocócica, la cual resulta del consumo de alimentos en los que Staphylococcus, principalmente $S$. aureus, está presente por encima de $10^{5} \mathrm{UFC} / \mathrm{g}$, sintetizando factores de virulencia, entre ellos, una familia de exoproteínas o exotoxinas con actividad superantigénica y pirógena (1).

La introducción de $S$. aureus en los alimentos procesados se debe, principalmente, a la contaminación aportada por los manipuladores. El nicho ecológico de $S$. aureus son las fosas nasales, sitio de donde se puede aislar con mayor frecuencia. En consecuencia, la aplicación de inadecuadas prácticas de manufactura facilitaría la presencia y el desarrollo del agente patógeno en los alimentos (2,3).

Un tipo de las exotoxinas superantigénicas y pirógenas producidas por $S$. aureus, posee una actividad de enterotoxina: las enterotoxinas. Su acción en el intestino delgado origina vómitos y diarreas por mecanismos no totalmente conocidos. La interacción inicial se lleva a cabo en el receptor del linfocito $\mathrm{T}$ y el complejo mayor de histocompatibilidad (CMH-II) de la célula presentadora de antígeno, la cual se activa por mecanismos suprantigénicos el sistema inmunitario y provoca una importante pérdida de agua. Las enterotoxinas de Staphylococcus (clasificadas serológicamente como SEA a SEU) son proteínas simples, termotolerantes y de bajo peso molecular (26.000 a $34.000 \mathrm{Da})(4)$.

Las cinco enterotoxinas detectadas más frecuentemente en intoxicaciones alimentarias son las identificadas como SEA a SEE (las clásicas). Estas han sido las primeras en ser identificadas y

Correspondencia:

Aníbal A. Brizzio, Servicio de Laboratorio, Agencia Santafesina de Seguridad Alimentaria ASSAI. Francia 2690, (3000) Santa Fe, Argentina.

Telefax: (+540) 34 2457-3718

anibal.brizzio@gmail.com

Recibido: 11/11/11; aceptado:24/08/12 estudiadas. Si bien ya se han reportado otros tipos de enteorotoxinas ( $F, G$, etc.), se desconoce su verdadera implicación en la salud pública (5).

La detección de enterotoxinas de Staphylococcus en un alimento (inmunodifusión en gel -método de referencia-, ELISA, ELFA, etc.) requiere de complejidad instrumental (costo elevado) y el desarrollo metodológico inherente (dificultades operativas). Por otra parte, la investigación de enterotoxinas de Staphylococcus en una cepa pura (inmunodifusión en gel -método de referencia-, RPLA, ELISA, ELFA, etc.) tiene un grado de dificultad considerable, aunque variable. Por su sencillez, la RPLA es una técnica difundida, pero con importantes limitaciones técnicas: dificultad de disponibilidad comercial, equipos comerciales que contemplan solo la detección de enterotoxinas clásicas y la existencia de reacciones cruzadas entre las mismas. Además, frecuentemente los niveles en que estas enterotoxinas son sintetizadas se encuentran por debajo de los limites de detección de las metodologías utilizadas (inmunoensayos en sus diferentes variantes) o su expresión se encuentra inhibida directamente por las condiciones del medio en el que se encuentra el microorganismo $(6,7)$.

El empleo de técnicas de la reacción en cadena de la polimerasa (PCR) ha permitido superar estas dificultades, siendo una herramienta eficaz y sencilla para establecer la presencia de genes de enterotoxinas en cepas de $S$. aureus. En este trabajo se presenta el desarrollo de una estrategia rápida, fiable y de bajo costo basado en una PCR múltiple para identificar simultáneamente $S$. aureus (por amplificación del gen de la nucleasa termoestable, nuc) y detectar los genes más conocidos de enterotoxinas de Staphylococcus (sea, seb, sec, sed, see), simultáneamente, en cepas aisladas de alimentos vinculados a brotes de intoxicación alimentaria.

\section{Materiales y métodos}

Se trabajó con aislamientos de muestras de alimentos de 12 brotes ocurridos en la provincia de Santa Fe. Las muestras de las cuales se obtuvieron 
los aislamientos fueron las siguientes: alimentos cárnicos, 3 (25\%); carne de aves elaboradas, 2 (16,6 \%); pescado elaborado, 2 (16,6 \%); sándwiches, 2 (16,6\%), y comidas elaboradas, 3 (25\%). Estos se recuperaron aplicando técnicas oficiales en el Laboratorio de Microbiología de Alimentos de la Agencia Santafesina de Seguridad Alimentaria (ASSAl, Santa Fe, Argentina) (8). Se utilizaron controles positivos (cepas salvajes productoras de enterotoxinas, cedidas por los centros de salud) y controles negativos ( $S$. aureus ATCC 25923), para la caracterización fenotípica y la evaluación genotípica.

Las cepas control y los aislamientos de Staphylococcus spp. de los 12 brotes, se identificaron a partir de un cultivo en agar cerebro-corazón (Merck, Alemania) incubado a $37^{\circ} \mathrm{C}$ durante $24 \mathrm{~h}$ en aerobiosis. Se verificó la presencia de catalasa, DNAsa (Merck, Alemania) y coagulasa (Merck, Alemania). Además, se hizo una coloración de Gram. Se efectuaron complementariamente las pruebas de producción de acetoína en caldo RM/ VP y reducción de nitrato en caldo cerebro-corazón (Laboratorios Britania, Argentina). Después se evaluó la capacidad de los aislamientos para fermentar hidratos de carbono (ICN Biomedials Inc., Ohio, USA) al $1 \%$ en caldo base de rojo fenol (Laboratorios Britania, Argentina).

El ADN genómico se extrajo como fuera reportado previamente (8), a partir de una a cinco colonias obtenidas por incubación en agar cerebro-corazón (Laboratorios Britania, Argentina) a $37^{\circ} \mathrm{C}$ durante 24 horas, que fueron suspendidas nuevamente en $150 \mu \mathrm{l}$ de agua bidestilada y calentadas durante
15 minutos a $100^{\circ} \mathrm{C}$. Posteriormente, el resultado de la extracción se centrifugó a $10.000 \mathrm{~g}$ durante 10 minutos, para eliminar restos celulares. El sobrenadante fue trasvasado a un tubo nuevo y almacenado a $-20{ }^{\circ} \mathrm{C}$, hasta su utilización en la reacción de amplificación.

Para la identificación de las cepas de $S$. aureus por PCR, se amplificó una secuencia del gen de la nucleasa termoestable (nuc), con los cebadores descritos por primera vez por Brakstad, et al.(9) (cuadro 1). Los oligonucleótidos cebadores empleados para identificar los genes de enterotoxinas (sea-see) fueron los propuestos por Sharma, et al. (10). Este diseño permite, en una sola reacción de amplificación, la detección de genes que codifican estas enterotoxinas. Se utiliza un cebador directo universal que se aparea a una región $5^{\prime}$ conservada y cinco oligonucleótidos cebadores inversos específicos para los cinco genes individuales que codifican cada una de las enterotoxinas clásicas (cuadro 1). Los productos de amplificación se habían confirmado previamente, utilizando una digestión con la enzima de restricción Rsal (8). La enzima apropiada se seleccionó mediante el análisis de las secuencias asistido por programas bioinformáticos disponibles en línea.

Además, todas las reacciones de PCR múltiple incluyeron la amplificación de una secuencia del gen ARNr 16S, como control interno de amplificación no competitivo.

Para evaluar la utilización simultánea de los oligonucleótidos cebadores propuestos, se hizo previamente un análisis in silico para verificar la

Cuadro 1. Secuencias de oligonucleótidos cebadores utilizados, tamaño de fragmentos obtenidos y número de acceso a bases de datos

\begin{tabular}{|c|c|c|c|}
\hline Molécula & Secuencia de oligonucleótidos & Producto de PCR & $\begin{array}{c}\text { Acceso en } \\
\text { Gene Bank N }\end{array}$ \\
\hline \multirow[t]{2}{*}{ sea } & 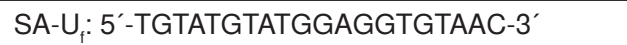 & & \\
\hline & SA-A: 5'-ATTAACCGAACGTTCTGT-'3 & $270 \mathrm{pb}$ & FJ495182 \\
\hline \multirow[t]{2}{*}{ seb } & SA-U: 5' $^{\prime}$-TGTATGTATGGAGGTGTAAC-3' & & \\
\hline & 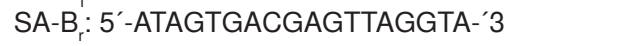 & $165 \mathrm{pb}$ & AB462490 \\
\hline \multirow[t]{2}{*}{$\sec$} & SA-Uf: 5'-TGTATGTATGGAGGTGTAAC-3' & & \\
\hline & SA-C : 5'-AATTGTGTTTCTTTTATTTTCATAA-'3 & $102 \mathrm{pb}$ & AM778682 \\
\hline \multirow[t]{2}{*}{ sed } & SA-U $U_{f}^{\prime} 5^{\prime}$-TGTATGTATGGAGGTGTAAC- $3^{\prime}$ & & \\
\hline & SA-D D $_{r}^{\prime}$-TTCGGGAAAATCACCCTTAA-3' & $303 \mathrm{pb}$ & DQ630751 \\
\hline \multirow[t]{2}{*}{ see } & SA-U $\mathrm{f}^{\prime} 5^{\prime}$-TGTATGTATGGAGGTGTAAC-3' & & \\
\hline & SA-E $\mathrm{E}_{r}$ 5'-GCCAAAGCTGTCTGAG-'3 & $213 \mathrm{pb}$ & AY518387 \\
\hline \multirow[t]{2}{*}{ nuc } & nucf: 5'- GCGATTGATGGTGATACGGTT-3' & & \\
\hline & nucr: 5'- AGCCAAGCCTTGACGAACTAAAGC-'3 & $279 \mathrm{pb}$ & СР002643 \\
\hline \multirow[t]{2}{*}{ ARNr16S } & DG74: 5'-AGGAGGTGATCCAACCGCA-3' & & \\
\hline & RW01 :5'-AACTGGAGGAAGGTGGGGAT-3' & $370 \mathrm{pb}$ & NR024570 \\
\hline
\end{tabular}


pertinencia de su uso en el ensayo de PCR múltiple aquí presentado.

La reacción de amplificación se preparó con 12,5 $\mu$ l de la solución tampón 2X GoTaq Green MasterMix Buffer $^{T m}(\mathrm{pH} 8,5)$ de Promega (Biodynamics SRL, Buenos Aires, Argentina), que contenía Taq ADN polimerasa, dNTPS y $\mathrm{MgCl}_{2}, 0,4 \mu \mathrm{M}$ de cada cebador (SA-U, SA-A, SA-B, SA-C, SA-D, SA-E, NUC, ARNr 16S) (Integrated DNA Technologies, Florida, USA), $2,5 \mu \mathrm{l}$ de la muestra de ADN y agua destilada estéril, en un volumen suficiente para 25 $\mu$ l. Se emplearon las siguientes condiciones de ciclado: incubación inicial a $95{ }^{\circ} \mathrm{C}$ durante cinco minutos, seguida por 30 ciclos de 15 segundos a $95^{\circ} \mathrm{C}$, apareamiento a $50^{\circ} \mathrm{C}$ durante 30 segundos y extensión final a $72^{\circ} \mathrm{C}$ por 30 segundos. El último ciclo consistió en una incubación a $72{ }^{\circ} \mathrm{C}$ durante 2 minutos.

Los productos de amplificación se analizaron por electroforesis en un gel de agarosa al $2 \%$ en presencia de $0,5 \mu \mathrm{g} / \mathrm{ml}$ de bromuro de etidio.

\section{Resultados}

Desde el punto de vista fenotípico, todos los aislamientos analizados se identificaron como $S$. aureus subespecie aureus.

En la figura 1a se presentan los perfiles típicos de PCR obtenidos con cepas controles productoras de un tipo de enterotoxina (con cebadores para los genes de enterotoxinas de Staphylococcus). Se muestra la especificidad de los cebadores, sin ninguna banda inespecífica adicional. Por otra parte, la figura $1 \mathrm{~b}$ representa lo que puede encontrarse al utilizar la PCR múltiple completa aquí presentada. En ella, se pueden ver tres bandas de amplificación por una cepa de $S$. aureus productor de enterotoxina $\mathrm{B}$ : una banda para el gen control $A R N r$ 16S, una para el gen nuc y otra para el gen de la enterotoxina (un perfil con el mismo número de bandas se encuentra en cepas que porten los genes de enterotoxinas $C$, $D$ y E). En caso de que la cepa posea el gen de la enterotoxina $A$, se observarán solo dos bandas debido a la superposición de los productos de amplificación de los genes sea y nuc (270 y 278 $\mathrm{pb}$, respectivamente). Para resolver este caso, se puede practicar una PCR simple para cada gen. La incorporación de este paso ulterior no implicaría una complicación, manteniéndose las ventajas operativas del método planteado.

Con el protocolo de PCR múltiple propuesto, nos abocamos al análisis de aislamientos recuperados de brotes de intoxicación alimentaria ocurridos en nuestra provincia. Las doce cepas analizadas de $S$. aureus resultaron ser positivas para coagulasa. De ellas, se detectaron 7 cepas (58 \%) portadoras de genes toxigénicos. Además, se pudo determinar que las toxinas sea y seb se encontraron en igual porcentaje (29\%), mientras que las sec, sed y see se encontraron en menor e idéntica proporción (14 $\%)$. Por otra parte, no se encontró más de un tipo diferente de enterotoxinas de Staphylococcus spp. en los aislamientos analizados. Estos hallazgos no muestran diferencias significativas con reportes previos, en los cuales se caracterizaron aislamientos de $S$. aureus vinculados con intoxicaciones alimentarias en nuestro país (3).

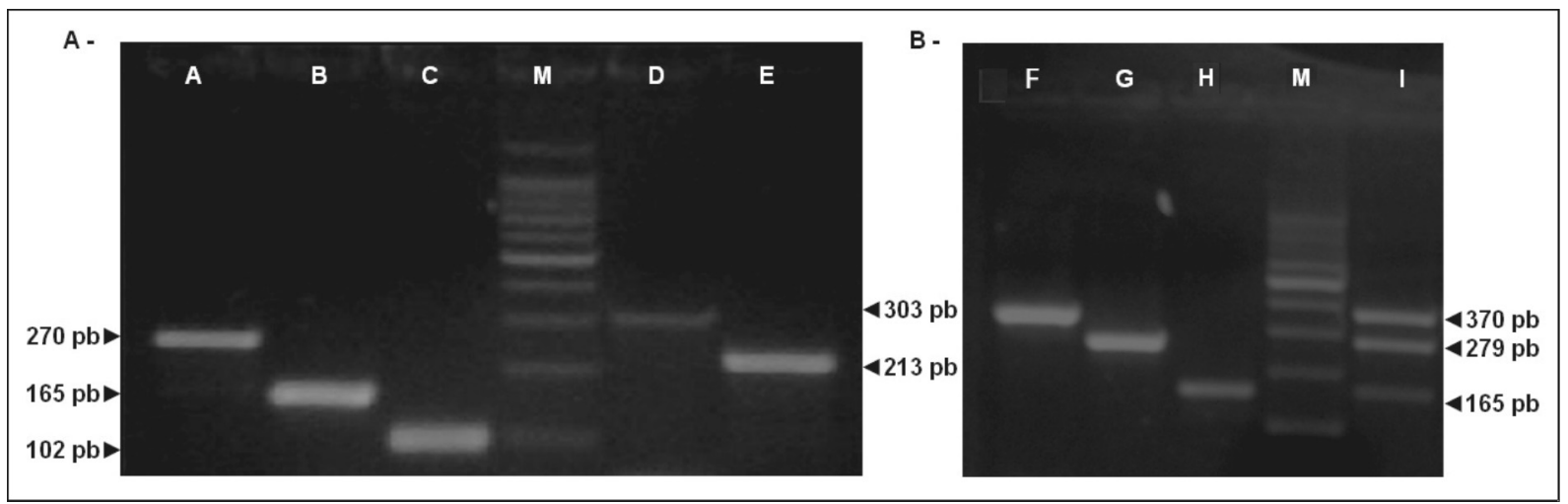

Figura 1. A) Amplificación individual de secuencias de genes de enterotoxinas de $S$. aureus a partir de muestras de ADN extraídas de cepas control. Calles A, B, C, D y E: S. aureus que contiene genes de enterotoxinas de $S$. aureus sea, seb, sec, sed y see, respectivamente; calle M, marcador de tamaño molecular (Cien Marker, Biodynamics, Argentina). B) Calles F, G y H: amplificación individual de secuencias de los genes $16 S$ rRNA, nuc y seb, respectivamente; calle I: PCR múltiple (para genes nuc, $16 S$ rRNA y de enterotoxinas de $S$. aureus en una muestra de ADN extraído de una cepa de $S$. aureus que contiene el gen para la enterotoxina B (seb); calle M: marcador de tamaño molecular (Cien Marker, Biodynamics, Argentina). 


\section{Discusión}

Staphylococcus aureus ocupa un papel destacado como agente etiológico de una de las gastroenteritis más frecuentes por consumo de alimentos contaminados, generando la afección conocida como intoxicación alimentaria estafilocócica, producto de la acción de exoproteínas secretadas por la bacteria en la luz intestinal. En consecuencia, desde el punto de vista epidemiológico, un desafío importante es el hecho de poder constatar de manera eficiente, ante un brote de intoxicación alimentaria estafilocócica, la presencia de $S$. aureus y su capacidad de generar enterotoxinas.

Hasta el momento, solo se cuenta con procedimientos para la detección inmunoquímica de un número limitado de enterotoxinas (principalmente, las clásicas). Además, con frecuencia los niveles de enterotoxinas en alimentos contaminados se encuentran por debajo de los límites de detección de los inmunoensayos empleados o su expresión se encuentra inhibida directamente por las condiciones del medio en el que se encuentra el microorganismo $(6,7)$.

En los últimos años se desarrollaron numerosas técnicas de PCR múltiple para la detección de genes que codifican las enterotoxinas de $S$. aureus $(11,12)$. Sin embargo, estos protocolos no permiten identificar $S$. aureus subespecie aureus y, al mismo tiempo, detectar en una misma PCR múltiple el número de genes que aquí se propone, o utilizan directamente cebadores específicos (directos e inversos para cada enterotoxina), lo cual aumenta la complejidad y el costo de la caracterización respecto a la metodología aquí detallada. Al igual que en trabajos recientes en que se evalúa un número mayor de genes de enterotoxinas de $S$. aureus recuperados de brotes de intoxicación alimentaria estafilocócica, en el presente trabajo las enterotoxinas $A$ y $B$ fueron la más frecuentemente identificadas (3).

Como es bien sabido, la definición de brote de intoxicación alimentaria estafilocócica implica la aparición de dos o más casos relacionados temporal y espacialmente, con aislamiento de una cepa de $S$. aureus productora de enterotoxinas. Reviste importancia trascendental, en consecuencia, poder confirmar eficientemente la identidad del microorganismo recuperado de los casos o los alimentos y demostrar su capacidad para la generación de enterotoxinas. En este contexto, en este trabajo se ofrece una estrategia rápida, fiable y de bajo costo para, simultáneamente, identificar S. aureus (por amplificación del gen de la nucleasa termoestable, nuc) y detectar los genes más conocidos de enterotoxinas, en cepas de Staphylococcus spp. En estos momentos, nuestros esfuerzos están dirigidos a desarrollar una segunda línea de PCR para detectar los genes que codifican las enterotoxinas y los factores de virulencia (13) no considerados en este trabajo, a fin de conocer su incidencia en las intoxicaciones alimentarias estafilocócicas, e investigar su relevancia en la salud pública de nuestro país.

\section{Conflicto de intereses}

Los autores declaran no tener conflictos de interés, financiero, político o académico, en la realización del presente trabajo.

\section{Financiación}

Este trabajo fue financiado en parte, por la Secretaría de Ciencia, Técnica e Innovación de la provincia de Santa Fe, Argentina. (Programación 2011, Fortalecimiento de las Capacidades del Sistema de Investigación y Desarrollo de la Provincia de Santa Fe, Proyecto 2010-062-11 "Detección y caracterización molecular de genes de enterotoxinas de Staphylococcus aureus en aislamientos de brotes de origen alimentario").

\section{Referencias}

1. Bhatia A, Zahoor S. Staphylococcus aureus enterotoxins: A review. J Clin Diag Res. 2007;3:188-97.

2. Figueroa GG, Navarrete PW, Caro MC, Troncoso MH, Faúndez GZ. Portación de Staphylococcus aureus enterotoxigénicos en manipuladores de alimentos. Rev Med Chile. 2002;130:859-64. http://dx.doi.org/10.4067/ S0034-98872002000800003

3. Manfredi EA, Leotta GA, RIVAS M. PCR múltiple para la detección de los genes sea, seb, sec, sed y see de Staphylococcus aureus. Caracterización de aislamientos de origen alimentario. Rev Argent Microbiol. 2010;42:212-5.

4. Le Loir Y, Baron F, Gautier M. Staphylococcus aureus and food poisoning. Genet Mol Res. 2003;2:63-76.

5. Lovseth A, Loncarevic S, Berdal K. Modified multiplex PCR methods for detection of pyrogenic exotoxin genes in staphylococcal isolates. J Clin Microbiol. 2004;42:3869-72. http://dx.doi.org/10.1128/JCM.42.8.3869-3872.2004

6. Aydin A, Sudagidan M, Muratoglu K. Prevalence of staphylococcal enterotoxins, toxin genes and geneticrelatedness of foodborne Staphylococcus aureus strains isolated in the Marmara Region of Turkey. Int $\mathrm{J}$ Food Microbiol.2011;148:99-106. http://dx.doi.org/10.1016/j.ijfood micro.2011.05.007

7. Hennekinne JA, Ostyn A, Guillier F, Herbin S, Prufer AL, Dragacci S. How should staphylococcal food poisoning outbreaks be characterized? Toxins (Basel). 2010;2:2106-6. http://dx.doi.org/10.3390/toxins2082106 
8. Brizzio AA, Tedeschi FA, Zalazar FE. Descripción de un brote de intoxicación alimentaria estafilocócica ocurrido en Las Rosas, Provincia de Santa Fe, Argentina. Rev Argent Microbiol. 2011;43:28-32.

9. Brakstad, OG, Aasbakk, K, Maelamd, JA. Detection of Staphylococcus aureus by polymerase chain reaction amplification of nuc gene. J Clin Microbiol. 1992;30:165460.

10. Sharma N, Rees C, Dodd C. Development of a singlereaction multiplex PCR toxin typing assay for Staphylococcus aureus strains. Appl Environ Microbiol. 2000;66:1347-53. http://dx.doi.org/10.1128/AEM.66.4.1347-1353.2000

11. Cha J, Lee J, Jung Y, Yoo J, Park Y, Kim B, et al. Molecular analysis of Staphylococcus aureus isolates associated with staphylococcal food poisoning in South Korea. J Appl Microbiol. 2006;101:864-71. http://dx.doi.org/10.1111/ j.1365-2672.2006.02957.x

12. Karahan M, Açik MN, Cetinkaya B. Investigation of toxin genes by polymerase chain reaction in Staphylococcus aureus strains isolated from bovine mastitis in Turkey. Foodborne Pathog Dis. 2009;6:1029-35. http://dx.doi. org/10.1089/fpd.2009.0304.

13. Bustos-Martínez J A, Hamdan-Partida A, GutiérrezCárdenas M. Staphylococcus aureus: la reemergencia de un patógeno en la comunidad. Rev Biomed. 2006;17:287305. 